Review

\title{
Extra-Corporeal Membrane Oxygenation Cadaver Donors: What about Tissues Used as Allografts?
}

\author{
Gregorio Marchiori ${ }^{1,+}+\mathbb{D}$, Matteo Berni ${ }^{2,+}+\mathbb{\infty}$, Giorgio Cassiolas ${ }^{3}$, Leonardo Vivarelli ${ }^{4, *}$,

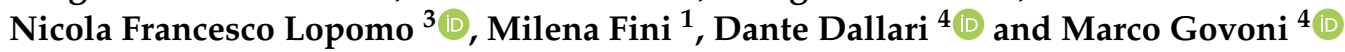 \\ 1 Surgical Sciences and Technologies Complex Structure, IRCCS Istituto Ortopedico Rizzoli, \\ Via di Barbiano 1/10, 40136 Bologna, Italy; gregorio.marchiori@ior.it (G.M.); milena.fini@ior.it (M.F.) \\ 2 Medical Technology Laboratory Complex Structure, IRCCS Istituto Ortopedico Rizzoli, Via di Barbiano 1/10, \\ 40136 Bologna, Italy; matteo.berni@ior.it \\ 3 Department of Information Engineering, University of Brescia, Via Branze 38, 25123 Brescia, Italy; \\ g.cassiolas@unibs.it (G.C.); nicola.lopomo@unibs.it (N.F.L.) \\ 4 Reconstructive Orthopaedic Surgery and Innovative Techniques-Musculoskeletal Tissue Bank, IRCCS \\ Istituto Ortopedico Rizzoli, Via G.C. Pupilli 1, 40136 Bologna, Italy; dante.dallari@ior.it (D.D.); \\ marco.govoni@ior.it (M.G.) \\ * Correspondence: leonardo.vivarelli@ior.it \\ + Equally contributed to this work as first authors.
}

check for updates

Citation: Marchiori, G.; Berni, M.; Cassiolas, G.; Vivarelli, L.; Lopomo, N.F.; Fini, M.; Dallari, D.; Govoni, M. Extra-Corporeal Membrane

Oxygenation Cadaver Donors: What about Tissues Used as Allografts?. Membranes 2021, 11, 545. https:// doi.org/10.3390/membranes11070545

Academic Editors: Gennaro Martucci, Antonio Arcadipane and Marco Giani

Received: 19 May 2021

Accepted: 16 July 2021

Published: 19 July 2021

Publisher's Note: MDPI stays neutral with regard to jurisdictional claims in published maps and institutional affiliations.

Copyright: (C) 2021 by the authors Licensee MDPI, Basel, Switzerland. This article is an open access article distributed under the terms and conditions of the Creative Commons Attribution (CC BY) license (https:/ / creativecommons.org/licenses/by/ $4.0 /)$.

\begin{abstract}
Several studies demonstrated the efficacy of post-mortem extracorporeal membrane oxygenation (ECMO) on donors in preserving organ function addressing organ transplantation. Nevertheless, no common and shared evidence was reached about the possibility of using ECMO donors in tissue harvesting. Therefore, this work aimed first to review the current scientific literature about ECMO donors, and then to focus on the use of ECMO tissues as allografts, mainly addressing musculoskeletal tissues, which are of the most interest for reconstruction. A search was conducted on the current scientific literature, focusing on the keywords "ECMO" and "Donor". Several online databases were used, including PubMed, Scopus, and Web of Science. From the preliminary search, 478 articles were obtained, out of which 173 specifically reported the use of ECMO for donation and transplantation purposes. Literature reported extensive analyses of ECMO organs-overall from the abdomen-both in pre- and post-transplantation studies. On the other hand, ECMO tissues were explanted only in a very limited number of cases; moreover, no information was referred about their status and use. A revision of the current scientific literature highlighted the lack of information concerning ECMO tissues and the necessity to perform preclinical, ex vivo studies to compare allografts from ECMO donors, with respect to standard donors, and, thus, to verify whether they can be harvested and implanted safely and with efficacy.
\end{abstract}

Keywords: extracorporeal membrane oxygenation; allografts; transplantation; cadaver donors; preclinical studies

\section{Introduction}

In the development and validation processes related to novel drugs and medical devices, it is standard practice to pass through in vitro/ex vivo assessments and in vivo animal models before moving on to clinical trials, to demonstrate the overall safety and expected benefits of the products. Concerning organ transplantation, the process may be different due to the urgency of the life-saving treatment and the persistent mismatch between supply and organ demand [1]. Indeed, these needs have been pushing to obtain new kinds of donors directly in clinics. Although clinical reports showed promising results, preclinical models remain important to optimize the procedure [2]. Further, pretransplant biopsies and analyses are fundamental to support clinicians in assessing the quality of the tissues [3]. 
In this perspective, although extracorporeal membrane oxygenation (ECMO, Figure 1), also known as regional perfusion, recirculation, or abdominal oxygenated recirculation [4], is a pivotal tool to support critically ill patients worldwide, post-mortem ECMO represents a promising solution and a viable option to expand the organ/tissue donation pool $[5,6]$. Therefore, as reported by Ortega-Deballon et al. (2015), many countries worldwide have explored the option of donation after circulatory death (i.e., donors after circulatory death-DCD) with the use of extracorporeal perfusion or in situ cooling protocols [7]. When cardiac death occurs in the hospital, DCD is defined as controlled (CDCD), since a decision has been made to withdraw life-sustaining treatments. In this scenario, consent for organ/tissue donation is always obtained by relatives before ECMO procedures begin. Otherwise, in the uncontrolled DCD ( $\mathrm{uDCD}$ ), death is unexpected and generally occurs out of the hospital. Therefore, cannulation and organ preservation with ECMO protocols or in situ cooling can generally begin after hospital arrival, where life-supporting devices are available. For $\mathrm{uDCD}$, consent requirements for donation and organ preservation vary by region or country and may occur before or after cannulation [7]. However, considering that ECMO procedure is an advanced and expensive technology [8], and the allocation of the organ(s) is urged by starting extracorporeal oxygenation strategies [9], it would be more appropriate to acquire the informed consent before cadaver donor cannulation. Further worldwide standardisation of $\mathrm{uDCD}$ guidelines is needed to achieve long-term success and widespread implementation of strategies aimed at expanding the number of eligible organ/tissue donors. Indeed, thanks to the ability of providing normal perfusion and oxygenation, ECMO procedure may regenerate cellular energy substrates and, therefore, it has the potential to improve viability of subsequently transplanted grafts [1,10,11]. Moreover, besides its reconditioning effect, ECMO allows organ function to be assessed prior to transplantation. Concerning tissue assessment, ECMO also confers the possibility of conducing intraoperative biopsies, which provide the chance to use reliable grafts [12,13]. However, treatment with ECMO also reported several side effects, such as blood cell consumption and activation [14], and risk of injury inherently related to the reperfusion process [15].

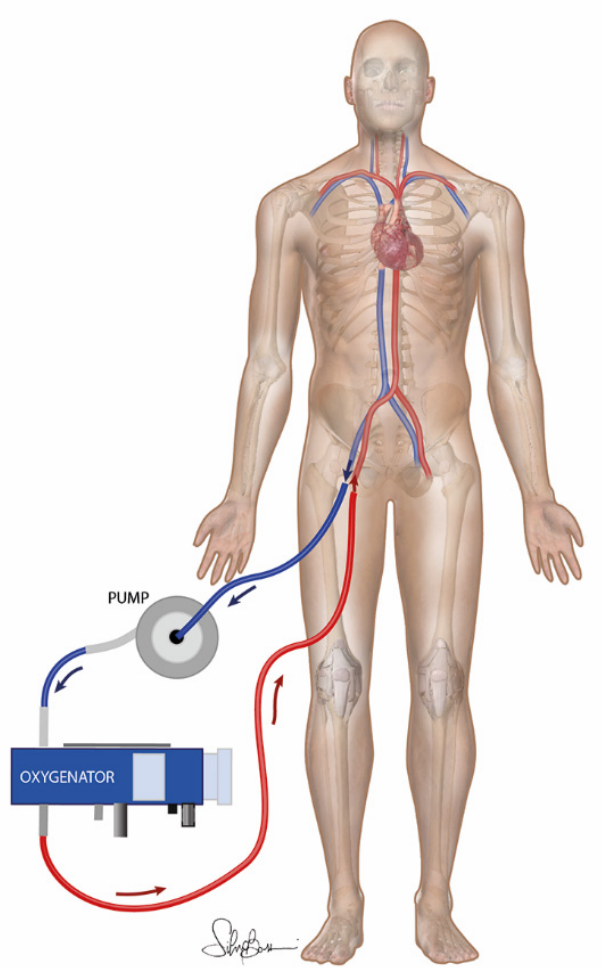

Figure 1. Sketch of the ECMO abdominal recirculation circuit on cadaver donor. 
Although a lot of information is available about organs in their entirety [16], tissues are worth investigating as well for two fundamental reasons: (1) to increase and improve the actual knowledge on ECMO organs, since an organ is a complex system consisting of various tissues and the tissue functional state should allow the organ to operate highlevel tasks at the best of its potentiality; (2) to reveal ECMO donors as potential new sources also for the banks of tissues, because single tissues can be harvested and used as allografts in reconstructive surgeries, e.g., valves in the heart [17], cornea in the eye [17], and ligaments/menisci in the knee $[18,19]$.

Regarding musculoskeletal allografts, as reported by several authors [20-22], bones and their soft tissue components, such as tendons and ligaments, are among the most frequent tissues transplanted worldwide (over two million grafting procedures per year), coming right after blood transfusion. The increasing number of grafting procedures performed every year is related to the ageing population, especially to the fastest-growing segment of individuals over the age of 65. Compared to the USA, where each year more than 900,000 allografts are used [23], in Europe, the trend of the allogeneic tissue transplant (normalised for the total population by country) is slightly lower, although musculoskeletal tissue demand is continuously growing. Some examples are listed, as follows: in France, from 2012 to 2016, the use of allogeneic long bones, femoral heads, and ligaments/tendons increased by $8.3 \%, 50.8 \%$, and $316.2 \%$, respectively [24]; in Germany, more than 30,000 allogeneic bone transplantations are performed every year [25]; in Italy, more than 10,000 allogeneic locomotor tissues are distributed per year, about 6000 of them by the Musculoskeletal Tissue Bank of the IRCCS Istituto Ortopedico Rizzoli (Musculoskeletal Tissue Bank internal data sources).

Accordingly, the objective of this paper is twofold: the first aim was to conduct a review of the current scientific literature to shed light on ECMO donors, and on the possibility of harvesting and testing ECMO tissues, whereas the second goal was to suggest indications to support the development of novel preclinical/preimplant studies, focusing in particular on musculoskeletal tissues, because these are the most diffused as allografts [26,27].

\section{Materials and Methods}

An in-depth search was conducted on several online databases including PubMed, Scopus, and Web of Science, with no restriction on date of publication up to the end of 2020.

During the first search, the keywords "ECMO" and "donor" were used. In the following screening phase, papers where perfusion was (i) directed to the recipient and not to the donor, (ii) conducted ex vivo (i.e., on the organ isolated from the donor before transplantation, "topical ECMO"), (iii) directed on a specific organ, or (iv) discussed only relatively to the determination of death for donation purposes, were excluded.

A second screening with the same requirements was finally performed on the referenced articles to complete the list. A flowchart is shown in Figure 2.

Analysis was performed by two separate reviewers, who checked the inclusion/exclusion criteria on each paper, first screening the abstract, and then the main text. The review focused on the typology of donated organs/tissues and the relative performed assessments.

The complete list of included papers in the synthesis is provided in the Supplementary Material, such as Table S1. 


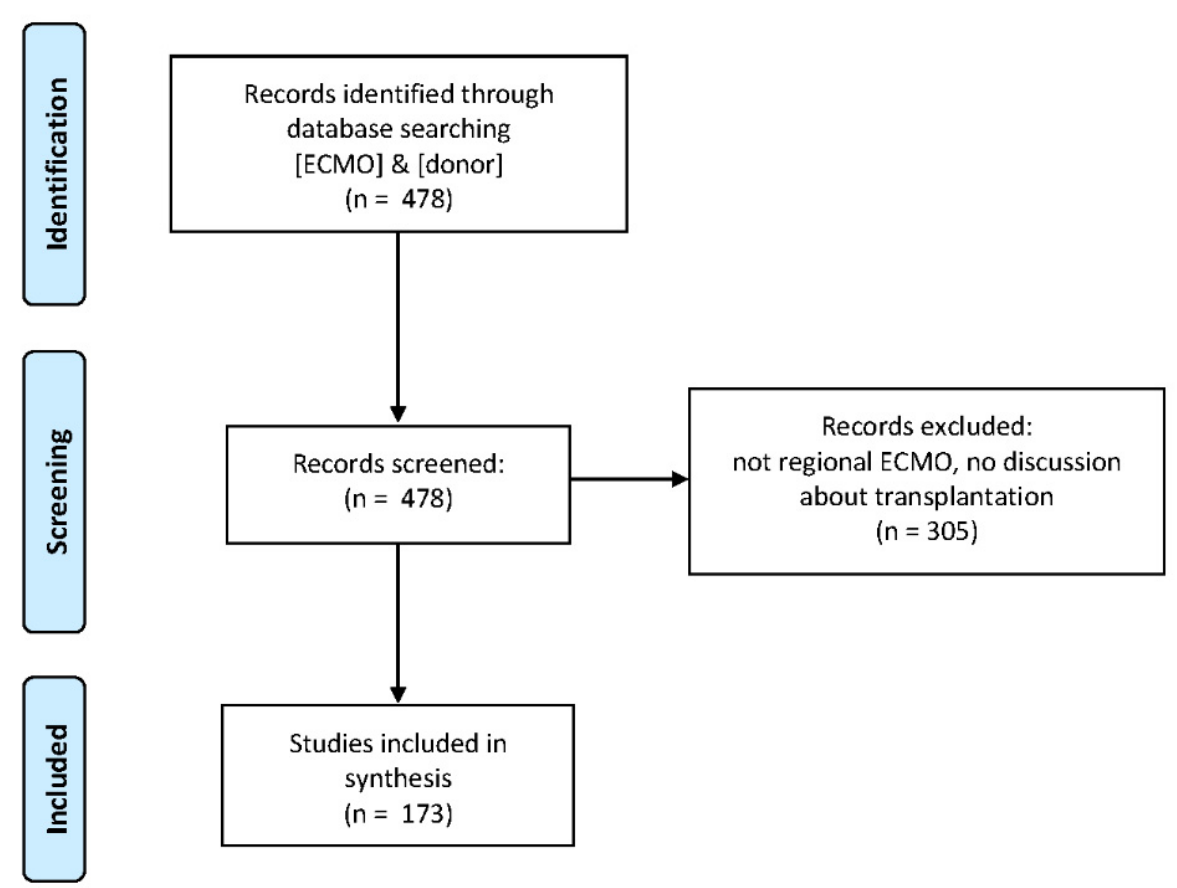

Figure 2. Flowchart showing study identification, screening, and inclusion.

\section{Results}

In the first phase, 478 studies were identified as possible candidates in this review. After the screening, 173 studies were selected for the synthesis (Figure 2), from 1963 to the end of 2020. First, they have been classified by considering the typology of the investigated tissues and organs (Figure 3).

\section{Grafts in studies with ECMO donor}

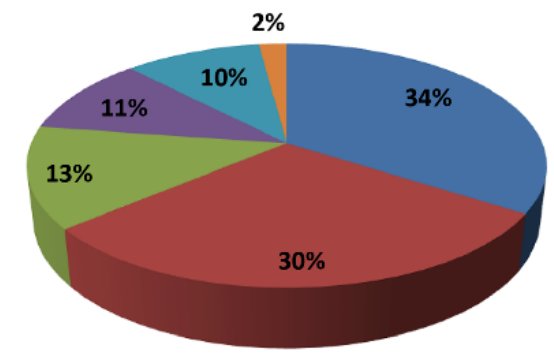

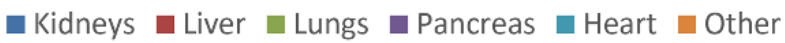

Figure 3. Classification of the identified studies by considering the organ.

The majority of the studies pertained to the abdominal organs - in particular, kidneys (34\%) [28], liver (30\%) [29], and pancreas (11\%) [30]-followed by the thoracic organs-lungs (13\%) and heart (10\%) [12]. Only $2 \%$ of the studies involved the harvesting of grafts pertaining different anatomical regions, including cornea $[13,17,31]$, gall bladder and choledochus [32], osteotendinous tissue [13,31], bowel [33], and vascular tissue [13]. A study reported the harvesting of even an entire limb (actually a "topical" ECMO) [34].

As shown in Figure 4, the studies were then classified as "review", "ex vivo", "in vivo on animals" (i.e., preclinical studies), and "in vivo on humans" (i.e., clinical studies). In particular, ex vivo refers to assessments performed on tissues in experimental conditions outside the organism, with the minimum alteration of natural conditions. This approach 
implies that ECMO was performed on the donor, but all the analyses were realized outside the donor and the recipient.

\section{Kind of studies with ECMO donor}

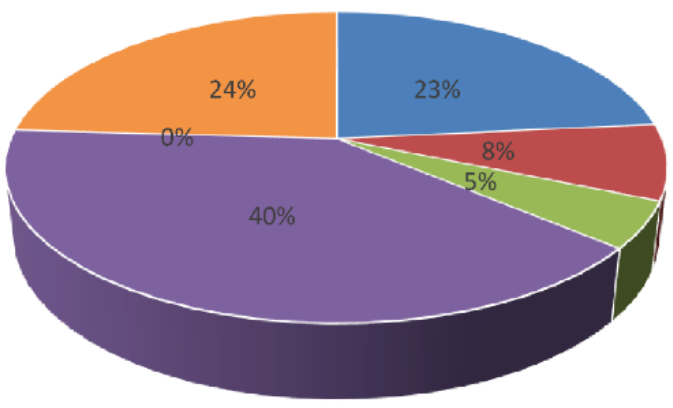

$$
\begin{aligned}
& \text { - Review } \quad \text { Ex vivo } \\
& \text { Ex vivo, in vivo on animals Ex vivo, in vivo on humans } \\
& \text { - In vivo on animals } \quad \text { In vivo on humans }
\end{aligned}
$$

Figure 4. Type of study including ECMO donors.

Reviews represented 23\% of the studies (e.g., in Christopher et al. [16]).

Ex vivo experiments without a transplantation phase-in which the graft was harvested from an ECMO donor and assessed, but not implanted in a recipient-pertained to $8 \%$ of the studies. Only one of these works treated human donors [1], while the remaining regarded animal donors [35]. The reported approaches highlighted the importance of preserving human grafts for transplant at the most.

On the contrary, ex vivo evaluations combined with analyses on transplanted animal recipients pertained to $5 \%$ of the studies (e.g., in Kerforne et al. 2019 [2]). Those studies performed on transplanted human recipients, relating graft and patient status, were the $40 \%$ (e.g., in Farney et al. [36]) and, therefore, the most important group.

Studies were labelled as "pure" in vivo (24\%) when focused on the graft functioning inside the recipient and/or on recipient survival. These studies were carried out directly on humans in the form of retrospective studies [37], case reports [38], or clinical trials [39].

Regarding the animal studies, the $87 \%$ treated porcine, two bovine $[40,41]$, one canine [41], and one rodent species [42]. The porcine preclinical model is the most diffused one due to size, anatomy, and cardiovascular physiology of the animal, very similar to those of human beings [43].

Most ex vivo investigations pertained to gross evaluation, gas/blood, and tissue biopsy analyses. These studies were performed in preimplant conditions to assess graft acceptability $[3,44]$, or in a postimplant phase to understand malfunctions and/or complications [45,46], or in both [36].

Despite the fact that experiences on ECMO donors are growing, to such an extent that various reviews on the theme have been recently published (Figure 5), only results about a reduced number of organs have been presented. 


\section{Studies about ECMO donors}

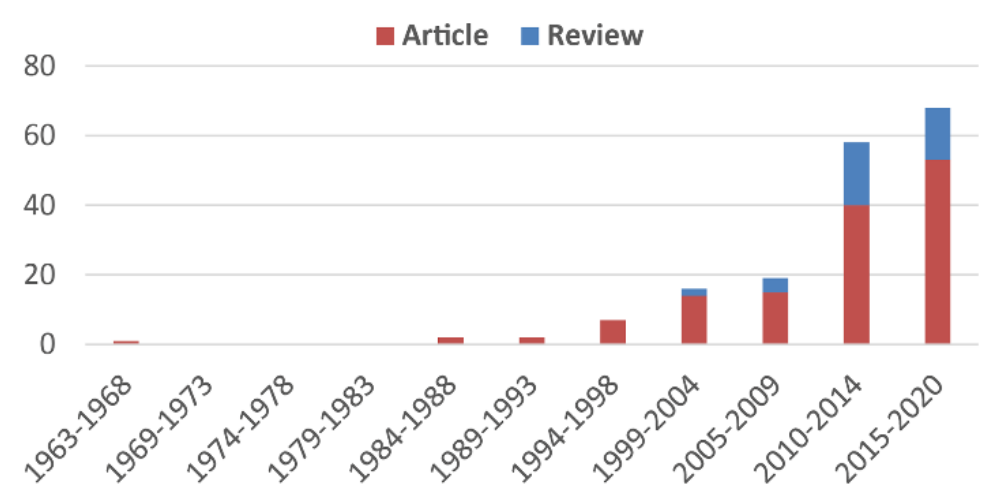

Figure 5. Studies about ECMO donors published from 1963 to 2020.

\section{Discussion}

Although literature agrees in giving ECMO the potentiality of expanding the overall number of available donors-among the found studies, only one, on rodents, did not find a positive effect of perfusion [42] - ECMO procedure is not without its own drawbacks. Nosocomial infections occurring during ECMO support or related to ECMO devices have already been reported [47]. Thus, to avoid possible contamination of donors' tissues and organs, a systematic blood culture and intravascular extremity cannula culture are needed and may help to verify device-related ECMO infection. Another potential issue to address is the risk of blood coagulation during the treatment. Indeed, blood proteins accumulate on the circuit membranes, causing membrane fouling, promoting the platelet and leukocyte aggregation to the membrane surfaces. Although heparin-coated membranes are used in many ECMO oxygenators, this solution does not seem to eliminate the risk of coagulation [48]. Thus, the potential formation of blood clots could reduce the oxygenation efficiency during the perfusion procedure and initiate the ischemic cascade in tissues and organs. Hence, an accurate analysis of all the monitored parameters during ECMO support, including also (i) mean perfusion time, (ii) time between donor death and beginning of the ECMO procedure, (iii) arterial and/or venous oxygen saturation, (iv) types of ECMO used (veno-venous or veno-arterial), and (v) type of membrane in the ECMO device (e.g., coating and/or material), is needed to properly evaluate and further preserve the quality of the transplanted organs and tissues.

Therefore, the assessment of tissue harvesting and use should receive more attention. In particular, cornea [31], gall bladder and choledocus [32], osteotendinous tissue, and vessels were harvested from ECMO donors [13], but nothing was shared about their status and fate.

Some promising indications can be identified in the study performed by Constantinescu et al. [34], addressing musculoskeletal tissue. In particular, they underlined how tissue preservation in limb extremities represents an important challenge. The authors were also able to perfuse porcine limbs ex vivo and assess tissue biopsies, demonstrating the potential of extracorporeal blood circulation in preserving muscles, blood vessels, and nerves. However, in that study, the authors implemented a condition of perfusion which was different from the regional ECMO. As a major flaw, the paper did not report information about ligaments, cartilage, or menisci. Indeed, a porcine model was used, but concerning-for instance-meniscal tissue, no known animal species give appropriate substitutes with respect to human tissue [49].

On the other hand, the capacity of bone, tendons, fat, and skin to tolerate ischemia has been already discussed [50,51].

Besides these few references on ECMO tissues in general, there is no evidence of preclinical studies comparing regional ECMO with respect to standard donors. They should be planned and carried out to assess the potentiality of the ECMO donor pool with 
statistical significance. If positive, clinical studies could then verify the real efficacy of ECMO tissue grafts.

Therefore, before starting to distribute musculoskeletal tissues harvested from ECMO donors, a study procedure should be proposed, starting directly from human donors, standing the non-use of vital organs. Experiments should focus on tissue structure/composition and function, thus, to exclude correlation between potential macroscopic alterations and the extracorporeal oxygenation procedure. The goal of this study should be the possibility to increase the overall number of tissue donors for allograft, thus, to make bone transplantation and joint reconstruction procedures feasible for more patients, guaranteeing, at the same time, the safety and quality of the harvested samples.

Regarding the structure and composition of tendons, histological and immunohistochemical analysis of biopsies are fundamental to provide information concerning cellularity, vascularity, fibrous matrix, and content of glycosaminoglycans (GAGs) [52]. Normal tendons are featured by organized, parallel fibre bundles and long, thin tenocytes dispersed throughout the matrix. On the other hand, pathological tendons may show various alterations, such as glassy appearance, loss of matrix organization, GAG accumulation, or intimal hyperplasia of blood vessels [53].

Although tendons and ligaments have many similarities in terms of structure, the latter shows a higher proteoglycan and water content and a lower amount of collagen. As for tendons, histology and immunohistochemical staining could provide information about collagen bundle width, fibril orientation, cell morphology and size, as well as crimp (i.e., a regular sinusoidal pattern in the matrix of collagen fibres [54]). Regarding menisci, lesions following trauma or related to osteoarthritis (OA) were fully described [55,56], though meniscus properties after ECMO seem to have never been systematically analysed. Therefore, dealing with structure and composition, the study procedure will establish protocols for representative macroscopic and histopathological analysis to exclude the presence of potential proteolytic degradation or other biochemical alterations [57].

Meanwhile, mechanical tests would give indications about function $[58,59]$. In the case of tendon grafts, the study protocol could be based, for instance, on the work of Zheng et al. [59]: grafts are tested in traction, standing that these tissues are mainly composed of fibres for resisting tension; testing groups are compared in terms of stiffness and ultimate failure at maximum load; they differed for the pretension force, while, in the study on ECMO, they would differ for the kind of donor. Similar discussion applies to meniscus grafts: testing protocol could be similar to that contained in the work of Sandmann et al. [58], where samples are loaded in compression, as in the main physiological functioning, and evaluated in terms of stiffness and residual force; the comparison was between different species and artificial constructs, while, in the study on ECMO, it would be between different kinds of human donor.

Indeed, mechanical testing could alter the sample; therefore, it should not precede histology. On the other hand, histology represents a standard assessment, but preparation is destructive (usually embedding and sections cutting), therefore, it cannot work on the same sample of the mechanical test. It follows that, if biopsy on which histology is performed decreases the mechanical strength of the tissue-mainly due to harvesting dimensions and/or location-two different groups of tissues are needed, one for each assessment (mechanical and histological), with an increase in experimental time and costs.

Finally, by comparing a group of samples harvested from standard donors with respect to a group coming from ECMO donors, it is possible to demonstrate that, statistically- that is on average - the two populations do not differ from each other. Nonetheless, although safety is guaranteed by microbiological testing, the evaluation of each specific graft before implantation remains fundamental [60], especially regarding suitability issues. For what is said above, in the case of musculoskeletal tissues, a biopsy could not be feasible because the process can alter the graft function. Therefore, gross evaluation and instruments sensing mechanical strength without altering the tissue are mandatory. Those instruments could be represented by a ligament tensioner in the case of anterior cruciate ligament grafts, as 
used in the study of Niki et al. (2019) for second-look arthroscopy [61], or by a blunt tip for sensing fibro-cartilaginous tissue consistency, as proposed by the International Cartilage Repair Society (IRCS) grading system [62].

Once the tissue grafts harvested from ECMO donors are declared to be potentially safe and effective, post-transplant clinical studies will state their effectiveness. As for organs, in vivo assessments should be focused both on implanted patients and on used allografts. In the case of musculoskeletal tissues, the patients could be evaluated through pain and activity scores [63], while grafts by biomedical imaging could be able to provide information about morphology and biochemistry [61,64-66].

\section{Conclusions}

Post-mortem extracorporeal membrane oxygenation (ECMO) is a potential way to expand the overall number of tissue donors for allografts. In order to verify its feasibility, tissues harvested from ECMO donors must be compared with those coming from standard donors by defining specific ex vivo experiments, which could be represented by histological analyses, and mechanical testing in the case of musculoskeletal tissue grafts.

Supplementary Materials: The following are available online at https://www.mdpi.com/article/ 10.3390/membranes11070545/s1, Table S1: Summary of specific details of studies included in the synthesis.

Author Contributions: G.M., M.B. and G.C. contributed to the research design, performance of research, writing, and reviewing of the article; M.G. contributed to the research design, and writing and reviewing of the article; L.V. contributed to data analysis, and to the writing and reviewing of the article; N.F.L. provided important intellectual content during manuscript revision; M.F. and D.D. contributed to the reviewing of the article. All authors have read and agreed to the published version of the manuscript.

Funding: This research was supported by " 5 per mille" funding, year 2018, provided by IRCCS Istituto Ortopedico Rizzoli.

Institutional Review Board Statement: Not applicable.

Informed Consent Statement: Not applicable.

Data Availability Statement: No new data were created or analysed in this study. Data sharing is not applicable to this article.

Acknowledgments: We thank Silvia Bassini, IRCCS Istituto Ortopedico Rizzoli staff, for iconographic material.

Conflicts of Interest: The authors declare no conflict of interest.

\section{References}

1. Peris, A.; Lazzeri, C.; Bonizzoli, M.; Guetti, C.; Tadini Buoninsegni, L.; Fulceri, G.; Ticali, P.F.; Chiostri, M.; Li Marzi, V.; Serni, S.; et al. A metabolic approach during normothermic regional perfusion in uncontrolled donors after circulatory death-a pilot study. Clin. Transpl. 2018, 32, e13387. [CrossRef] [PubMed]

2. Kerforne, T.; Allain, G.; Giraud, S.; Bon, D.; Ameteau, V.; Couturier, P.; Hebrard, W.; Danion, J.; Goujon, J.M.; Thuillier, R.; et al. Defining the optimal duration for normothermic regional perfusion in the kidney donor: A porcine preclinical study. Am. J. Transpl. 2019, 19, 737-751. [CrossRef] [PubMed]

3. Kojc, N.; Perse, M.; Plesko, J.; Veceric-Haler, Z. Early graft loss after kidney transplantation: Endothelial dysfunction of renal microvasculature. BioMed Res. Int. 2018, 2018, 4074209. [CrossRef] [PubMed]

4. Butler, A.J.; Randle, L.V.; Watson, C.J. Normothermic regional perfusion for donation after circulatory death without prior heparinization. Transplantation 2014, 97, 1272-1278. [CrossRef]

5. De Carlis, R.; Di Sandro, S.; Lauterio, A.; Botta, F.; Ferla, F.; Andorno, E.; Bagnardi, V.; De Carlis, L. Liver grafts from donors after circulatory death on regional perfusion with extended warm ischemia compared with donors after brain death. Liver Transpl. 2018, 24, 1523-1535. [CrossRef]

6. Magliocca, J.F.; Magee, J.C.; Rowe, S.A.; Gravel, M.T.; Chenault, R.H., II; Merion, R.M.; Punch, J.D.; Bartlett, R.H.; Hemmila, M.R. Extracorporeal support for organ donation after cardiac death effectively expands the donor pool. J. Trauma Acute Care Surg. 2005, 58, 1095-1102. [CrossRef] [PubMed] 
7. Ortega-Deballon, I.; Hornby, L.; Shemie, S.D. Protocols for uncontrolled donation after circulatory death: A systematic review of international guidelines, practices and transplant outcomes. Crit. Care 2015, 19, 268. [CrossRef]

8. Oude Lansink-Hartgring, A.; van Minnen, O.; Vermeulen, K.M.; van den Bergh, W.M. Dutch Extracorporeal Life Support Study Group. Hospital costs of extracorporeal membrane oxygenation in adults: A systematic review. Pharm. Open 2021, 1-11. [CrossRef]

9. Fazekas, L.; Sax, B.; Hartyanszky, I.; Polos, M.; Horkay, F.; Varga, T.; Racz, K.; Nemeth, E.; Szekely, A.; Paulovich, E.; et al. Mechanical circulatory support saves lives-three years' experience of the newly established assist device program at semmelweis university, budapest, hungary. Orv. Hetil. 2015, 156, 521-527. [CrossRef]

10. Fischer, J.H.; Funcke, C.; Yotsumoto, G.; Jeschkeit-Schubbert, S.; Kuhn-Regnier, F. Maintenance of physiological coronary endothelial function after $3.3 \mathrm{~h}$ of hypothermic oxygen persufflation preservation and orthotopic transplantation of non-heartbeating donor hearts. Eur. J. Cardiothorac. Surg. 2004, 25, 98-104. [CrossRef]

11. Gravel, M.T.; Arenas, J.D.; Chenault, R., II; Magee, J.C.; Rudich, S.; Maraschio, M.; DebRoy, M.; Miller, W.; Punch, J.D. Kidney transplantation from organ donors following cardiopulmonary death using extracorporeal membrane oxygenation support. Ann. Transplant. 2004, 9, 57-58. [PubMed]

12. Minambres, E.; Rubio, J.J.; Coll, E.; Dominguez-Gil, B. Donation after circulatory death and its expansion in spain. Curr. Opin. Organ Transplant. 2018, 23, 120-129. [CrossRef] [PubMed]

13. Perez-Villares, J.M.; Lara-Rosales, R. Interhospital transfers of a mobile team for organ preservation with extracorporeal membrane oxygenation in controlled donors after circulatory death. Med. Intensiva 2018, 42, 131-133. [CrossRef] [PubMed]

14. Adrian, K.; Skogby, M.; Friberg, L.G.; Mellgren, K. The effect of s-nitroso-glutathione on platelet and leukocyte function during experimental extracorporeal circulation. Artif. Organs 2003, 27, 570-575. [CrossRef]

15. Vos, I.H.; Joles, J.A.; Rabelink, T.J. The role of nitric oxide in renal transplantation. Semin. Nephrol. 2004, 24, 379-388. [CrossRef]

16. Christopher, D.A.; Woodside, K.J. Expanding the donor pool: Organ donation after brain death for extracorporeal membrane oxygenation patients. Crit. Care Med. 2017, 45, 1790-1791. [CrossRef]

17. Isnardi, D.I.; Olivero, F.; Lerda, R.; Guermani, A.; Cornara, G. Extracorporeal membrane oxygenation as a bridge to organ donation: A case report. Transplant. Proc. 2013, 45, 2619-2620. [CrossRef]

18. Grassi, A.; Bailey, J.R.; Filardo, G.; Samuelsson, K.; Zaffagnini, S.; Amendola, A. Return to sport activity after meniscal allograft transplantation: At what level and at what cost? A systematic review and meta-analysis. Sports Health 2019, 11, 123-133. [CrossRef]

19. Zaffagnini, S.; Grassi, A.; Marcheggiani Muccioli, G.M.; Roberti Di Sarsina, T.; Raggi, F.; Benzi, A.; Marcacci, M. Anterior cruciate ligament reconstruction with a novel porcine xenograft: The initial italian experience. Joints 2015, 3, 85-90. [CrossRef]

20. Campana, V.; Milano, G.; Pagano, E.; Barba, M.; Cicione, C.; Salonna, G.; Lattanzi, W.; Logroscino, G. Bone substitutes in orthopaedic surgery: From basic science to clinical practice. J. Mater. Sci. Mater. Med. 2014, 25, 2445-2461. [CrossRef]

21. de Girolamo, L.; Ragni, E.; Cucchiarini, M.; van Bergen, C.J.A.; Hunziker, E.B.; Chubinskaya, S. Cells, soluble factors and matrix harmonically play the concert of allograft integration. Knee Surg. Sports Traumatol. Arthrosc. 2019, 27, 1717-1725. [CrossRef]

22. Lavernia, C.J.; Malinin, T.I.; Temple, H.T.; Moreyra, C.E. Bone and tissue allograft use by orthopaedic surgeons. J. Arthroplast. 2004, 19, 430-435. [CrossRef]

23. Saha, P.C.; Roy, S. Musculoskeletal tissue banking: In orthopaedic perspective. IOSR J. Dent. Med. Sci. 2013, 11, 64-68. [CrossRef]

24. Erivan, R.; Villatte, G.; Ollivier, M.; Descamps, S.; Boisgard, S. Update on the supply and use of allografts in locomotor system pathologies in france. Orthop. Traumatol. Surg. Res. 2018, 104, 1125-1130. [CrossRef]

25. Botiss Biomaterials. Allogenic Bone Grafts: Same Safety as Pharmaceutical Products. Available online: https://botiss.com/ allogenic-bone-grafts-same-safety-as-pharmaceutical-products/ (accessed on 15 July 2021).

26. Giedraitis, A.; Arnoczky, S.P.; Bedi, A. Allografts in soft tissue reconstructive procedures: Important considerations. Sports Health 2014, 6, 256-264. [CrossRef]

27. Singh, R.; Singh, D.; Singh, A. Radiation sterilization of tissue allografts: A review. World J. Radiol. 2016, 8, 355-369. [CrossRef]

28. Wind, J.; Hoogland, E.R.; van Heurn, L.W. Preservation techniques for donors after cardiac death kidneys. Curr. Opin. Organ. Transplant. 2011, 16, 157-161. [CrossRef]

29. Guarrera, J.V. Donation: Where are our opportunities for expansion? Liver Transpl. 2014, 20, S2-S4. [CrossRef]

30. Butt, W.; MacLaren, G. Extracorporeal membrane oxygenation 2016: An update. F1000Research 2016, 5, 750. [CrossRef]

31. Mateos Rodriguez, A.A.; Navalpotro Pascual, J.M.; del Rio Gallegos, F. Lung transplant of extrahospitalary donor after cardiac death. Am. J. Emerg. Med. 2013, 31, 710-711. [CrossRef]

32. Fondevila, C.; Hessheimer, A.J.; Flores, E.; Ruiz, A.; Mestres, N.; Calatayud, D.; Paredes, D.; Rodriguez, C.; Fuster, J.; Navasa, M.; et al. Applicability and results of maastricht type 2 donation after cardiac death liver transplantation. Am. J. Transplant. 2012, 12, 162-170. [CrossRef]

33. Guo, M.; Yao, D.; Li, L.; Lu, C.; Li, Y.; Li, J. Intestinal conditioning after cardiac arrest: The use of normothermic extracorporeal membrane oxygenation in the non-heart-beating animal model. Artif. Organs 2016, 40, 738-745. [CrossRef] [PubMed]

34. Constantinescu, M.A.; Knall, E.; Xu, X.; Kiermeir, D.M.; Jenni, H.; Gygax, E.; Rieben, R.; Banic, A.; Vogelin, E. Preservation of amputated extremities by extracorporeal blood perfusion; a feasibility study in a porcine model. J. Surg. Res. 2011, 171, 291-299. [CrossRef] 
35. Hagiwara, M.; Matsuno, N.; Meng, L.T.; Furukori, M.; Watanabe, K.; Shonaka, T.; Imai, K.; Obara, H.; Nishikawa, Y.; Furukawa, H. Applicability of combined use of extracorporeal support and temperature-controlled machine perfusion preservation for liver procurement of donors after cardiac death in pigs. Transplant. Proc. 2016, 48, 1234-1238. [CrossRef] [PubMed]

36. Farney, A.C.; Singh, R.P.; Hines, M.H.; Rogers, J.; Hartmann, E.L.; Reeves-Daniel, A.; Gautreaux, M.D.; Iskandar, S.S.; Adams, P.L.; Stratta, R.J. Experience in renal and extrarenal transplantation with donation after cardiac death donors with selective use of extracorporeal support. J. Am. Coll. Surg. 2008, 206, 1028-1037. [CrossRef]

37. Bronchard, R.; Durand, L.; Legeai, C.; Cohen, J.; Guerrini, P.; Bastien, O. Brain-dead donors on extracorporeal membrane oxygenation. Crit. Care Med. 2017, 45, 1734-1741. [CrossRef]

38. Kim, Y.H.; Sohn, G.Y.; Jung, Y.J.; Kyoung, K.H.; Hong, S.K. Successful management of potential non-heart-beating donor with extracorporeal membrane oxygenation: A case report. Korean J. Crit. Care Med. 2012, 27, 279-282. [CrossRef]

39. Reznik, O.; Skvortsov, A.; Loginov, I.; Ananyev, A.; Bagnenko, S.; Moysyuk, Y. Kidney from uncontrolled donors after cardiac death with one hour warm ischemic time: Resuscitation by extracorporal normothermic abdominal perfusion "in situ" by leukocytes-free oxygenated blood. Clin. Transplant. 2011, 25, 511-516. [CrossRef]

40. Kontos, G.J., Jr.; Adachi, H.; Borkon, M.A.; Cameron, D.E.; Baumgartner, W.A.; Hutchins, G.M.; Brawn, J.; Reitz, B.A. A no-flush, core-cooling technique for successful cardiopulmonary preservation in heart-lung transplantation. J. Thorac. Cardiovasc. Surg. 1987, 94, 836-842. [CrossRef]

41. Marchioro, T.L.; Huntley, R.T.; Waddell, W.R.; Starzl, T.E. Extracorporeal perfusion for obtaining postmortem homografts. Surgery 1963, 54, 900-911.

42. Moers, C.; van Rijt, G.; Ploeg, R.J.; Leuvenink, H.G. The effect of normothermic recirculation before cold preservation on post-transplant injury of ischemically damaged donor kidneys. Transpl. Int. 2012, 25, 210-217. [CrossRef] [PubMed]

43. Allain, G.; Kerforne, T.; Thuret, R.; Delpech, P.O.; Saint-Yves, T.; Pinsard, M.; Hauet, T.; Giraud, S.; Jayle, C.; Barrou, B. Development of a preclinical model of donation after circulatory determination of death for translational application. Transplant. Res. 2014, 3, 13. [CrossRef]

44. Chiang, P.J.; Tang, S.H.; Li, C.C.; Chou, M.H.; Lin, Y.C.; Wu, S.T. Kidney transplantation from an extracorporeal membrane oxygenation-supported brain-dead donor: A case report. Medicine 2018, 97, e11106. [CrossRef]

45. Chen, K.H.; Tsai, M.K.; Ko, W.J.; Chen, Y.S.; Chueh, S.C.; Lai, M.K.; Lee, C.J.; Lee, P.H. Renal transplantation from non-heartbeating donors with extracorporeal membrane oxygenation: Preliminary results. Transplant. Proc. 2000, 32, 1743-1744. [CrossRef]

46. Matillon, X.; Danjou, F.; Petruzzo, P.; Thaunat, O.; Rimmele, T.; Delsuc, C.; Faure, A.; Rabeyrin, M.; Meas Yedid, V.; Hanf, W.; et al. Hypothermic pulsatile preservation of kidneys from uncontrolled deceased donors after cardiac arrest - a retrospective study. Transpl. Int. 2017, 30, 1284-1291. [CrossRef]

47. Thomas, G.; Hraiech, S.; Cassir, N.; Lehingue, S.; Rambaud, R.; Wiramus, S.; Guervilly, C.; Klasen, F.; Adda, M.; Dizier, S.; et al. Venovenous extracorporeal membrane oxygenation devices-related colonisations and infections. Ann. Intensive Care 2017, 7, 111. [CrossRef]

48. Obstals, F.; Vorobii, M.; Riedel, T.; de Los Santos Pereira, A.; Bruns, M.; Singh, S.; Rodriguez-Emmenegger, C. Improving hemocompatibility of membranes for extracorporeal membrane oxygenators by grafting nonthrombogenic polymer brushes. Macromol. Biosci. 2018, 18. [CrossRef] [PubMed]

49. Chia, H.N.; Hull, M.L. Compressive moduli of the human medial meniscus in the axial and radial directions at equilibrium and at a physiological strain rate. J. Orthop. Res. 2008, 26, 951-956. [CrossRef]

50. Biemer, E.; Moore-Heidecke, S.; Steinau, H.U.; Encke, A. Major Limb Replantation and Postischemia Syndrome: Investigation of Acute ischemia-Induced Myopathy and Reperfusion Injury; Springer: Berlin/Heidelberg, Germany, 2013; 126p.

51. Blaisdell, F.W. The pathophysiology of skeletal muscle ischemia and the reperfusion syndrome: A review. Cardiovasc. Surg. 2002, 10, 620-630. [CrossRef]

52. Hadjicostas, P.T.; Soucacos, P.N.; Koleganova, N.; Krohmer, G.; Berger, I. Comparative and morphological analysis of commonly used autografts for anterior cruciate ligament reconstruction with the native acl: An electron, microscopic and morphologic study. Knee Surg. Sports Traumatol. Arthrosc. 2008, 16, 1099-1107. [CrossRef]

53. Riley, G. Tendon and ligament biochemistry and pathology. In Sports Injuries; Hutson, M., Speed, C., Eds.; Oxford University Press: Oxford, UK, 2011; pp. 3-39.

54. Lane, J.G.; Amiel, D. Ligament histology, composition, anatomy, injury, and healing mechanisms. In Bio-Orthopaedics: A New Approach; Gobbi, A., Espregueira-Mendes, J., Lane, J.G., Karahan, M., Eds.; Springer: Berlin/Heidelberg, Germany, 2017; pp. 291-312.

55. Lohmander, L.S.; Englund, P.M.; Dahl, L.L.; Roos, E.M. The long-term consequence of anterior cruciate ligament and meniscus injuries: Osteoarthritis. Am. J. Sports Med. 2007, 35, 1756-1769. [CrossRef]

56. Pauli, C.; Grogan, S.P.; Patil, S.; Otsuki, S.; Hasegawa, A.; Koziol, J.; Lotz, M.K.; D’Lima, D.D. Macroscopic and histopathologic analysis of human knee menisci in aging and osteoarthritis. Osteoarthr. Cartil. 2011, 19, 1132-1141. [CrossRef]

57. Kestila, I.; Folkesson, E.; Finnila, M.A.; Turkiewicz, A.; Onnerfjord, P.; Hughes, V.; Tjornstrand, J.; Englund, M.; Saarakkala, S. Three-dimensional microstructure of human meniscus posterior horn in health and osteoarthritis. Osteoarthr. Cartil. 2019. [CrossRef] 
58. Sandmann, G.H.; Adamczyk, C.; Grande Garcia, E.; Doebele, S.; Buettner, A.; Milz, S.; Imhoff, A.B.; Vogt, S.; Burgkart, R.; Tischer, T. Biomechanical comparison of menisci from different species and artificial constructs. BMC Musculoskelet. Disord. 2013, 14, 324. [CrossRef] [PubMed]

59. Zheng, X.; Xu, W.; Gu, J.; Hu, Y.; Cui, M.; Feng, Y.E.; Gao, S. Effects of graft preconditioning on gamma-irradiated deep frozen tendon allografts used in anterior cruciate ligament reconstruction. Exp. Ther. Med. 2018, 16, 1338-1342.

60. Lazzeri, C.; Bonizzoli, M.; Marra, F.; Muiesan, P.; Ghinolfi, D.; De Simone, P.; Nesi, M.G.; Migliaccio, M.L.; Peris, A. Uncontrolled donation after circulatory death and liver transplantation: Evidence and unresolved issues. Minerva Anestesiol. 2019. [CrossRef]

61. Niki, Y.; Yasuoka, T.; Kobayashi, S.; Harato, K.; Nagura, T.; Okuda, S.; Jinzaki, M. Feasibility of t1rho and t2 map magnetic resonance imaging for evaluating graft maturation after anatomic double-bundle anterior cruciate ligament reconstruction. $J$. Orthop. Surg. Res. 2019, 14, 140. [CrossRef]

62. Aurich, M.; Hofmann, G.O.; Rolauffs, B.; Gras, F. Differences in injury pattern and prevalence of cartilage lesions in knee and ankle joints: A retrospective cohort study. Orthop. Rev. 2014, 6, 5611. [CrossRef]

63. Shimizu, T.; Cheng, Z.; Samaan, M.A.; Tanaka, M.S.; Souza, R.B.; Li, X.; Ma, C.B. Increases in joint laxity after anterior cruciate ligament reconstruction are associated with sagittal biomechanical asymmetry. Arthroscopy 2019, 35, 2072-2079. [CrossRef] [PubMed]

64. Braun, H.J.; Gold, G.E. Diagnosis of osteoarthritis: Imaging. Bone 2012, 51, 278-288. [CrossRef]

65. Lammentausta, E.; Kiviranta, P.; Toyras, J.; Hyttinen, M.M.; Kiviranta, I.; Nieminen, M.T.; Jurvelin, J.S. Quantitative mri of parallel changes of articular cartilage and underlying trabecular bone in degeneration. Osteoarthr. Cartil. 2007, 15, 1149-1157. [CrossRef]

66. Tsai, P.H.; Chou, M.C.; Lee, H.S.; Lee, C.H.; Chung, H.W.; Chang, Y.C.; Huang, G.S. Mr t2 values of the knee menisci in the healthy young population: Zonal and sex differences. Osteoarthr. Cartil. 2009, 17, 988-994. [CrossRef] 